\title{
Computational Characterization of Structural Role of the Non-active Site Mutation M36I of Human Immunodeficiency Virus Type 1 Protease
}

\author{
Hirotaka Ode ${ }^{1 *}$, Shou Matsuyama ${ }^{1}$, Masayuki Hata ${ }^{1}$, Saburo Neya ${ }^{1}$, \\ Junko Kakizawa ${ }^{2}$, Wataru Sugiura ${ }^{2}$, Tyuji Hoshino ${ }^{1,3}$
}

The Short Running Title

Characterization of the M36I mutation of HIV-1 PR

\section{Five Keywords}

HIV-1, protease, resistance, M36I, non-active site mutation

\section{CORRESPONDING AUTHOR FOOTNOTE}

* Corresponding author

Tel: $\quad+81-43-290-2926$

Fax: $+81-43-290-2925$

E-mail: $\quad$ odehir@graduate.chiba-u.jp

\section{INSTITUTION ADDRESS FOOTNOTE}

1 Graduate School of Pharmaceutical Sciences, Chiba University, 1-33 Yayoi-cho, Inage-ku, Chiba 263-8522, Japan

2 AIDS Research Center, National Institute of Infectious Diseases, 4-7-1 Gakuen, Musashimurayama, Tokyo 208-1011, Japan

3 also PRESTO, JST, 4-1-8 Honcho, Kawaguchi, Saitama 332-0012, Japan 


\section{Summary}

A prominent characteristic of human immunodefic iency virus type 1 (HIV-1) is its high

genetic variability, which generates diversity of the virus and often causes a serious problem of the emergence of drug-res is tant mutants. Subtype B HIV-1 is dominant in advanced countries, and the mortality rate due to subtype B HIV-1 has been decreased during the past decade. In contrast, the number of patients with non-subtype B viruses is still increasing in developing countries. One of the reas ons for the prevalence of non-subtype $B$ viruses is lack of information about the biological and therapeutic differences between subtype B and non-subtype B viruses. M36I is the most frequently observed polymorphism in non-subtype B HIV-1 proteases. However, since the 36 th residue is located at a non-active site of the protease and has no direct interaction with any ligands, the structural role of M36I remains unclear. In this study, we performed molecular dynamics (MD) simulations of M36I protease in complex with nelfinavir and revealed the influence of the M36I mutation. The results show that M36I regulates the size of the binding cavity of the protease. The reason for the rare emergence of D30N variants in non-subtype B HIV-1 proteases was also clarified from our computational analysis. 


\section{Introduc tion}

Human immunodeficiency virus type $1(\mathrm{HIV}-1)$ is one of the most hazardous viruses for humans. HIV-1 has a high genetic variability and has been classified into three groups: $\mathrm{M}, \mathrm{N}$, and $\mathrm{O}$ groups. Viruses in group $M$ are further subdivided into subtypes, sub-subtypes, and circulating recombinant forms (CRFs). The subtype B virus is commonly found in HIV-1-infected patients in North America, Europe, and Japan. Some anti-HIV-1 drugs that target viral proteins (reverse transcriptase, aspartic protease, and fusion proteins) have been clinically used and have lowered the death rate due to acquired immune defic iency syndrome (AIDS) in advanced countries during the past decade. In contrast, developing countries are suffering from a growing ep idemic of non-subtype B virus es. The number of patients infected with HIV-1 is still increas ing in developing countries. ${ }^{1}$

HIV-1 proliferates under the assistance of its own aspartic protease, so-called HIV-1 protease (HIV-1 PR), in its life cycle. ${ }^{2}$ HIV-1 PR is an enzyme composed of two identical polypeptides, each of which consists of 99 amino acid residues (Fig. 1a), and has a function to process the viral Gag and Gag-Pol polyprotein precursors. Because this processing is essential for viral maturation, inhibition of the PR function leads to incomplete viral replication and prevents the transfer to other human cells. ${ }^{3}$ Therefore, HIV-1 PR is an attractive target for anti-HIV-1 drugs. Nine PR inhibitors (PIs) have been approved by the Food and Drug Administration (FDA). ${ }^{4-12}$ Nevertheless, the currently available PIs were developed and tested only against subtype B PRs. Some studies have shown that non-subtype B viruses show different responses than the responses of subtype B virus to those P Is. ${ }^{13-18}$ Ariyoshi et al. reported that the patterns of emergence of res is tant mutations against nelfinavir (NFV, Fig. 1b) differed between subtype B and CRF01_AE HIV $-1 .{ }^{17}$ D30N predominantly appears in patients who are infected with 
subtype B HIV-1, and treatment with NFV has failed. D30N specifically confers resistance against NFV. ${ }^{19,20}$ In contrast, N88S predominantly appears in patients with CRF01_AE HIV-1. D30N is not found in patients with CRF01_AE HIV-1. D30N has also rarely been found in patients with other non-subtype B HIV-1. ${ }^{21-24}$ However, there have been few studies on the susceptibility of non-subtype B virus es to the presently availab le PIs, and a standard protocol of chemotherapy for non-subtype B viruses has not yet been es tablished. ${ }^{25}$

Non-subtype B HIV-1 PRs have natural polymorphis ms. Among those polymorphisms, M36I is the most frequently observed in patients with non-subtype B HIV-1. ${ }^{24,26,27}$ M36I is known to be related to resistance against some FDA-approved PIs: NFV, ind inavir, ritonavir, and atazanavir. ${ }^{20}$ Therefore, M36I is a key mutation to understand the difference between subtype B and non-subtype B HIV-1 PRs. Nevertheless, the structural role of the non-active site mutation M36I remains unclear. This is because the 36th residue of PR is not located at the active site of PR and has no direct in teraction with any substrates or any PIs.

In this study, we investigated the structural role of M36I of PR in the binding of PR with NFV through computational simulations. We also examined the structural role of M36V in order to compare the effect of the side chain at the 36 th residue. Some previous computational simulations have revealed structural ro les of non-active site mutations of HIV-1 PR. ${ }^{28-34}$ Our simulations indicated that the mutations at the 36th res idues influence the volume of the bind ing cavity of the active site of PR. The influence on the volume alters the interaction between D30 of PR and NFV. We also investigated the relationship between $\mathrm{D} 30 \mathrm{~N}$ and the mutation at the 36th residue of PR. Our results revealed that a 
combination of $\mathrm{D} 30 \mathrm{~N}$ and the mutation at the 36th residue induces the formation of hydrogen bonds between N30 of PR and NFV, which are not observed in PR with a single D30N mutation in complex with NFV. Our simulations suggest that M36I, despite the fact that it is a mutation at a non-active site, regulates the binding of ligands with PR. These find ings will be helpful for developing more effective PIs against non-subtype B HIV-1. 


\section{Results}

Hydrogen bond networks. We performed MD simulations of six subtype B HIV-1 PRs in complex with NFV: wild-type (WT) PR, M36I PR, M36V PR, D30N PR, D30N/M36I PR, and D30N/M36V PR (labeled as B(WT), B(M36I), B(M36V), B(D30N), B(D30N/M36I), and B(D30N/M36V), respectively). First, in order to clarify the structural role of the mutation at the 36 th residue, we examined direct or one-water-molecule-mediated hydrogen bonds between each PR and NFV (Table 1, Supporting Material Table S1). According to the X-ray structure of HIV-1 PR bound to NFV, ${ }^{35} \mathrm{NFV}$ has direct and one-water-molecule-mediated hydrogen bonds with D25/D25', I50/I50', D29', and D30 (Supporting Material Fig. S1). In all of the six models, the side chains of D25 and D25' directly interacted with the central hydroxyl group of NFV (O3 in Fig. 1b). All of models also have one-water-molecule-mediated hydrogen bonds of NFV with I50/I50' and with D29'. Different hydrogen bonds are observed between the 30th residue and the phenol group of NFV. In $\mathrm{B}(\mathrm{WT})$ and $\mathrm{B}(\mathrm{M} 36 \mathrm{~V})$, either the main chain or the side chain of D30 interacts with NFV through hydrogen bonds (Fig. 2). In B(M36I), only the side chain of D30 forms a hydrogen bond with NFV. In contrast, B(D30N) has no hydrogen bond with NFV. $\mathrm{B}(\mathrm{D} 30 \mathrm{~N} / \mathrm{M} 36 \mathrm{I})$ and $\mathrm{B}(\mathrm{D} 30 \mathrm{~N} / \mathrm{M} 36 \mathrm{~V})$ show a different feature from that of $\mathrm{B}(\mathrm{D} 30 \mathrm{~N})$. They have direct hydrogen bonds between the main chain of N30 and NFV.

Change in conformation of PR. Next, we inves tigated the $d$ ifference in the average structure of each PR from that of $\mathrm{B}(\mathrm{WT})$. The average structure of each PR was generated from 1000 snapshot structures during the last $1.0 \mathrm{~ns}$ MD simulations. In order to make a comparis on between each PR and of B(WT), we superimposed the average structure of each PR onto that of $\mathrm{B}(\mathrm{WT})$ using the coord inates of $\mathrm{N}, \mathrm{C} \alpha$, and $\mathrm{C}$ atoms. Since non-active site residues are more flex ib le than active site residues and the structure of non-active site residues is largely influenced by random atom motions in MD simulation (Supporting 
Materia1 Fig. S2), we focused on conformational change of the active site residues. Fig. 3 shows that the displacements of most of the active site residues are small. Detailed values are shown in Supporting Material Fig. S3. Exceptionally, a large conformational change (RMSD=1.5 $\AA$ ) is observed at $\mathrm{D} 29$ in B(D30N/M36I). In the other PRs, D29 is shifted about $0.7 \AA$. D30 is notic eably displaced by $0.8 \AA$ in only $\mathrm{B}(\mathrm{D} 30 \mathrm{~N})$, while displacement of the 30 th residues is less than $0.5 \AA$ in the other PRs. At a flap region and around 80's loops, slight conformational changes are also observed. The flap and 80's loop consist of the 47 th to 50 th residues and of the 79 th to 81 st residues, respectively. Although HIV-1 PR is a homodimer, the asymmetric displacements are observed. The displacement in NFV was also examined (Supporting Material Fig. S4). Conformational changes in the benzamide group and the S-phenyl group (C6H6-S-) are observed. B(D30N) and B(D30N/M36I) show larger displacement than that of the other models. In contrast, the tert-butylcarboxamide mo iety and the dodecahydroisoquinoline ring hardly change their locations in each model. The displacements of NFV are also as ymmetric and correlate with the displacements of PR. The residues near the benzamide group of NFV, such as the 29th and 30th residues, show large displacement. On the other hand, the residues near the tert-butylcarboxamide moiety or the dodecahydrois oquinoline ring of NFV show small displacements. The asymmetric displac ements obs erved in HIV-1 PR will be due to the structural collision with NFV.

Furthermore, we examined the effect of the mutation at the 36 th residue on volume of the active site (Table 2). M36I reduces the volume of the active site, whereas both D30N and D30N/M36I increase it. M36V and D30N/M36V have almost no effect on the volume.

Binding energy calculations. Binding energy between each PR and NFV is presented in Table 3. A single M36I or M36V mutation has almost no effect on the binding affinity with NFV, although the 
binding energy calculations have large standard deviations. In contrast, D30N and D30N/M36I mutations reduce the binding energies with NFV. Oppositely, D30N/M36V increases the affinity. Clemente et al. reported the IC50 values of $\mathrm{B}(\mathrm{WT}), \mathrm{B}(\mathrm{D} 30 \mathrm{~N}), \mathrm{B}(\mathrm{M} 36 \mathrm{I})$, and $\mathrm{B}(\mathrm{D} 30 \mathrm{~N} / \mathrm{M} 36 \mathrm{I}),{ }^{36}$ in which M36I was suggested to improve the binding affinity with NFV, and showed that D30N/M36I conferred res istance against NFV. Our results are compatible with tho se experimental results.

We additionally analyzed the contribution of each residue to the binding of NFV (Supporting Material Fig. S5). In B(M36I), B(M36V), and B(D30N/M36V), the respective residues except D25/D25' have contributions similar to those in $\mathrm{B}(\mathrm{WT})$. The contribution of $\mathrm{D} 25 / \mathrm{D} 25$ ' depends on their protonation states. In contrast, $\mathrm{B}(\mathrm{D} 30 \mathrm{~N})$ reduces the binding energy between the 30 th residue and NFV. B(D30N/M36I) lowers the interaction between D29 and NFV. 


\section{Discussion}

In this study, we performed MD simulations of HIV-1 PRs in complex with NFV for the purpose of clarifying (1) the structural role of the non-active site mutation M36I and (2) the relationship between D30N and M36I mutations. M36V was also examined in order to analyze the effect of the side chain of the 36 th residue.

Non-subtype B HIV-1 is still pandemic in the world. ${ }^{1}$ Nevertheless, a standard protocol of chemotherapy for non-subtype B viruses has not yet been established, ${ }^{25}$ and little is known about the difference between susceptib ilities of non-subtype B virus es and subtype B virus to clinically available drugs. ${ }^{13-18}$ M36I is the most frequently observed polymorphism among non-subtype B HIV-1 PRs. ${ }^{24,26,27}$ Therefore, M36I is a key mutation to clarify the reason why the effic acy of PIs varies among subtypes. Some studies have indicated that M36I is related to the res is tance against NFV and other FDA-approved PIs by complementing the effects of other res is tant mutations. ${ }^{17,20,34,36}$ For example, M36I has been shown to contribute to an increase in the emergence rate of the NFV-resistant mutation N88S. ${ }^{17,34}$ It has also been reported that a single M36I mutation does not confer resistance against FDA-approved PIs. ${ }^{36}$ The structural role of M36I is, however, not clear bec ause the 36th residue of PR is located at a non-active site of HIV-1 PR. According to the results of the present simulations, a single M36I mutation reduces the volume of the binding cavity of subtype B HIV-1 PR. Energetically, M36I PR slightly increases the binding affinity with NFV, compared with WT PR. This result is compatible with an experimental

finding. ${ }^{36}$ A single M36V mutation also reduces the volume of the cavity, although the effect of M36V on the cavity volume is not as great as that of M36I. When we carried out the additional 2.0ns MD simulation of each model, the reduction of the volume of the active site of M36I PR and that of M36V PR 
were also observed (Supporting Material Table S2). Therefore, the side chain of the 36th residue will indeed in fluence the shape of the active site of PR, despite its location.

In order to reveal the mechanism by which the non-active site mutation M36I regulates the volume of the active site of PR, we additionally calculated the interaction energy between each residue of PR and the 36th residue. The energy calculations suggest that the 36th residue mainly interacts with I15/I15', Q18/Q18', K20/K20', L33/L33', and V77/V77' (Supporting Material Fig. S6). Among these residues, L33/L33' and V77/V77' are located near active site residues (Fig. 4). V77/V77' is close to the 80's loop, which consists of the residues from $\mathrm{P} 79 / \mathrm{P} 79$ ' to $\mathrm{P} 81 / \mathrm{P} 81$ '. L33/L33' is in the vic inity of T31/T31'. Interestingly, mutations at L33 and V77 (L33F and V77I) are also related to the resistance against some PIs. ${ }^{20}$ These mutations would play a role similar to that of M36I. We speculate that the slight inward shifts of L33/L33' and V77/V77' due to the mutation M36I trigger the reduction in volume of the cavity of PR. In order to confirm this speculation, we further examined the shift of each residue and extracted the shift only toward the center of the active site (F ig. 5, Supporting Materials Fig. S7-S9). The results show that M36I causes a shrinkage of the active site around P79 and around T31'. The 31st residue T31/T31' creates stable hydrogen bond networks with D29, T74, and N88 or with D29', T74', and N88' (Supporting Material Table S3). ${ }^{28,34}$ Therefore, M36I also indirectly influences the conformations around D29/D29'. A28', D29', D30', and T31' in one monomer are all dis placed inward. In contrast, A28 and D29 show outward positional shifts, while the residues around L33 in the other monomer move inward. It is notable that these residues rotate on D30. M36I hardly shrinks or expands the cavity at D30. However, D30 shifts toward the $\alpha$-helix region (R87-I93) in B(M36I) (Supporting Material Fig. S 10). Although this displacement is very slight $(0.4 \AA)$, the shift enlarges the distance from the main chain of D30 to the $m$-phenol group of NFV, and it also shortens the distance from the side 
chain of D30 to NFV (Fig. 2). Therefore, M36I changes the interaction between D30 and NFV. D30 is an important residue for binding with NFV. ${ }^{28,34,35} \mathrm{~B}(\mathrm{M} 36 \mathrm{I})$ has a hydrogen bond of the $m$-phenol group of NFV only with the side chain of D30 unlike B(WT). B(WT) forms hydrogen bonds of the $m$-phenol group of NFV with either the main chain or the side chain of D30. These results show that the non-active site mutation M36I influence the shape of the active site of PR by the following mechanism. M36I mutation shifts L33/L33' and V77/V77' inward. Subsequently, those shifts cause change in conformations at the active site, especially around T31/T31' and P79/P79'.

It is also informative to inves tigate the relationship between D30N and M36I. As stated in the introduction section, most of the non-subtype B HIV-1 PRs carry M36I as a polymorphism. ${ }^{24,26,27}$ In contrast, D30N rarely appears in non-subtype B HIV-1 PRs. ${ }^{21-24}$ This rare emergence of D30N in non-subtype B PRs has been assumed to be due to the low viral replication ability of D30N mutants in non-subtype B viruses, ${ }^{22,37}$ because L89M, which is a polymorphism of some non-subtype B PRs, and D30N decrease the replication ability. ${ }^{22,37}$ On the other hand, our simulations provide a novel insight about the relationship between D30N and M36I. It should be noted that B(D30N/M36I) forms a hydrogen bond between the main chain of N30 and NFV (Fig. 2), which is not seen in B(D30N). M36I enforces the interaction between N30 and NFV in D30N mutant PR. A clear difference is observed at D29 among B(WT), B(M36I), B(D30N), and B(D30N/M36I) (Fig. 5). D29 in B(D30N/M36I) shows a large outward positional shift from that of $\mathrm{B}(\mathrm{WT})$. The shift of $\mathrm{B}(\mathrm{D} 30 \mathrm{~N} / \mathrm{M} 36 \mathrm{I})$ is two-times larger than that of $\mathrm{B}(\mathrm{M} 36 \mathrm{I})$ and $B(D 30 N)$. Binding energy calculations show that D30N/M36I lowers the binding affinity of NFV with subtype B PR (Table 3) and greatly reduces the interaction between D29 and NFV. D30N/M36I mutant of subtype B PR was reported to confer resistance against NFV. ${ }^{36}$ This energetical result is compatible with experimental findings. ${ }^{36}$ These results suggest that the res istance mechanism due to 
D30N/M36I is different from that of D30N. D30N causes resistance against NFV because of the loss of hydrogen bonds between $\mathrm{N} 30$ and $\mathrm{NFV} \cdot{ }^{28,34}$ On the other hand, D30N/M36I confers res is tance against NFV due to the large change in conformation at D29. NFV still in teracts with N30 in B(D30N/M36I). It is known that D30N is not observed in CRF01_AE PR. ${ }^{17}$ As we previously reported, ${ }^{34}$ this observation is explained from the finding that the affinity of CRF01_AE D30N PR with NFV is similar to that of CRF01_AE reference PR. CRF01_AE D30N PR has stronger interaction with NFV than does subtype B D30N PR. CRF01_AE D30N PR has one-water-mo lecule-mediated hydrogen bonds between NFV and N30, whereas subtype B D30N PR forms no hydrogen bond between them. M36I enforc es the in teraction between N30 and NFV, and polymorphisms other than M36I will release the dis tortion at D29. NFV will be able to maintain its efficacy against D30N mutant PR in non-subtype B viruses. Therefore, D30N mutation is rarely observed in non-subtype B HIV-1 PRs.

In this study, we performed MD simulations of six HIV-1 PRs in complex with NFV and clarify the structural role of the non-active site mutation M36I. M36I influences the shape of the active site of PR in spite of its location. The change in conformations at the active site is caused by the alteration of interaction of the 36th residue with L33 and V77. We also examined the relationship between D30N and M36I. A combination of D30N and M36I enforces the interaction between N30 and NFV, causing distortion on the conformation around D29. D30N/M36I shows a different mechanism of res is tance against NFV from that of D30N. M36I is the most frequently observed mutation in non-subtype B PRs. Therefore, M36I is a key mutation to understand the differences between subtype B and non-subtype B PRs. The findings of this study provide valuable information for developing the drugs that are more effective for non-subtype B PRs. Furthermore, accumulation of information on structural roles of key residues of PR will enable us to predict the effectiveness of PIs against non-subtype B virus es as well as 
against subtype B ones. 


\section{Acknowledgments}

This work was supported by a Health and Labor Science Res earch Grant for Research on HIV/AIDS from the Minis try of Health and Labor of Japan and by JSPS Research Fellowships for Young Scientists and a grant-in-aid for JSPS Fellows. A part of this work was also supported by a grant-in-aid from Japan Society for the Promotion of Science, No. 19590467. And by a grant from the Japan Science and Techno logy Agency.

Supple mentary Materias is a vailable on IDEAL. 


\section{Materials and Me thods}

Molecular dynamics (MD) simulation. We performed minimizations and MD simulations in a manner similar to that described elsewhere. ${ }^{34}$ Minimizations and MD simulations were carried out using the Sander module of the AMBER8 package. ${ }^{38}$ The AMBER ff03 force field ${ }^{39}$ was used as the parameters for proteins, ions, and water molecules. Our originally developed torsion parameters for the benzamide moiety in NFV, CA-CA-C -N and CA-CA-C -O, were applied. ${ }^{34}$ The general AMBER force field ${ }^{40}$ was used as other parameters for NFV. RESP charges for NFV were determined on the basis of data obtained from quantum chemical calculations. ${ }^{34}$

We performed simulations of six proteas es (PRs) in complex with NFV: wild-type (WT) PR, M36I PR, M36V PR, D30N PR, D30N/M36I PR, and D30N/M36V PR of subtype B HIV-1 (labeled as $\mathrm{B}(\mathrm{WT}), \mathrm{B}(\mathrm{M} 36 \mathrm{I}), \mathrm{B}(\mathrm{M} 36 \mathrm{~V}), \mathrm{B}(\mathrm{D} 30 \mathrm{~N}), \mathrm{B}(\mathrm{D} 30 \mathrm{~N} / \mathrm{M} 36 \mathrm{I})$, and $\mathrm{B}(\mathrm{D} 30 \mathrm{~N} / \mathrm{M} 36 \mathrm{~V})$, respectively). B(M36V) and $\mathrm{B}(\mathrm{D} 30 \mathrm{~N} / \mathrm{M} 36 \mathrm{~V})$ were examined in order to analyze the effect of the side chain of the 36th residue much clearly. We used HXB2 as the WT sequence of subtype B HIV-1. Each in itial structure for the PR in complex with NFV was modeled from the atom coordinates of an X-ray crystal structure (PDB code: $1 \mathrm{OHR}^{35}$ ) and the respective mutations were introduced using the LEaP module. First, we obtained the PDB file of the PR bound to NFV from Protein Data Bank (http $/ /$ www.pdb.org/). Second, we edited the PDB file to change the residue names of the mutated residues and to delete the information on the coordinates of the side chain atoms of the mutated residues. Third, the coordinates of the side chain atoms of the mutated residues were automatic ally generated by LEaP module. Fourth, each model was placed in a rectangular box filled with about 8000 TIP3P water molecules, ${ }^{41}$ with all of the crystal water molecules remaining. The cutoff distance for the long-range electrostatic and the van der Waals energy terms was set to $12.0 \AA$. The expansion and shrinkage of all covalent bonds connecting to a hydrogen atom were 
constrained using the SHAKE algorith ${ }^{42}$ Periodic boundary conditions were applied to avoid the edge effect in all calculations. Energy minimization was achieved in three steps. First, movement was allowed only for water molecules and ions. Next, the ligand and the mutated residues were allowed to move in addition to the water molecules and ions. In this step, steric collis ions of the automatically generated residues were minimized and favorable configurations of the side chains of the mutated residues were obtained. Finally, all atoms were permitted to move freely. In each step, energy minimization was executed by the steepest descent method for the first 10000 cycles and the conjugated gradient method for the subsequent 10000 cycles. After a $0.1 \mathrm{~ns}$ heating calculation until $310 \mathrm{~K}$ using the NVT ens emble, a $3.0 \mathrm{~ns}$ equilibrating calculation was executed at $1 \mathrm{~atm}$ and at $310 \mathrm{~K}$ using the NPT ensemble, with an integration time step of $2.0 \mathrm{fs}$. In the present calculations, the MD simulations showed no large fluctuations after about $2.0 \mathrm{~ns}$ equilibrating calculation (Supporting Materials Fig. S11, S12). Hence, atom coordinates were collected at in tervals of $1.0 \mathrm{ps}$ for the last $1.0 \mathrm{~ns}$ to analyze the structure in detail. Furthermore, we performed the additiona12.0 ns simulation for each model and confirmed equilibrium of each simulation (Supporting Material F ig. S13).

Protonation states of the catalytic aspartic acids D25 and D25' vary depending on the binding ligands or PRs. ${ }^{43}$ Hence, appropriate protonation states of the catalytic aspartic acids should be determined for each model. Since NFV mimics a transition state of catalytic reaction by HIV-1 PR, we considered two kinds of protonation states. ${ }^{44-46}$ One complex represented a combination of protonated D25 / unprotonated D25' states, and the other represented the opposite combination. In order to determine the protonation states when NFV is bound to each PR, the free energies of two kinds of complexes were compared using calculation data obtained during the 2.0-3.0 ns MD s imulations (Supporting Material Table S4). The free energies were calculated on the basis of the MM/PBSA method. ${ }^{47,48}$ We used the 
same parameter set for electros tatic and van der Waals energy terms as that used in the MD simulations, and no cutoff was applied for the calculation. Since the dielectric constants for the interior of proteins is considered to be in the range of 2 to 4 , the interio $r$ dielectric cons tant was set to $2.0 .^{49}$ The outer dielectric constant was set to 80.0. The pbsa program was used to solve the Poisson-Boltzmman (PB) equation. $\mathrm{B}(\mathrm{D} 30 \mathrm{~N}), \mathrm{B}(\mathrm{M} 36 \mathrm{I})$, and $\mathrm{B}(\mathrm{D} 30 \mathrm{~N} / \mathrm{M} 36 \mathrm{I})$ have been found to favor the combination of protonated D25 and unprotonated $\mathrm{D} 25^{\prime}$. The other three PRs, B(WT), B(M36V) and $\mathrm{B}(\mathrm{D} 30 \mathrm{~N} / \mathrm{M} 36 \mathrm{~V})$, prefer the combination of unprotonated D25 and protonated D25'.

Hydrogen bond criteria. The formation of a hydrogen bond was defined in terms of distance and orientation. The combination of donor D, hydrogen $\mathrm{H}$, and acceptor A atoms with a D - H ... A configuration was regarded as a hydrogen bond when the distance between donor D and acceptor A was shorter than $3.5 \AA$ and the angle H-D-A was smaller than 60.0 degrees.

\section{Calculations of volume and surface a rea of the binding cavity.}

We employed the Pocket program ${ }^{50}$ to estimate the volume and the surface area of the active site of PR. The program is based on the Alpha Shape theory, ${ }^{50}$ which provides an analytical method for detecting pockets in proteins and meas uring their volume and surface area. The ligand-bind ing cavity of HIV-1 PR is not completely separated from solvent. However, it should be noted that, in the Pocket program, a pocket is defined as a cavity which is inaccessible to the solvent outside of a protein. If a water molecule is trapped with in the pocket, the water molecule cannot escape to the outside of the protein. Hence, we can define the ligand-binding cavity as a pocket. Supproting Material Fig. S14 shows the bind ing pocket of HIV-1 PR visualized by MAGE program. ${ }^{51}$

Binding free energy calculation. The bind ing free energy ${ }^{52}$ was calculated by the following equation:

$$
\Delta \mathrm{G}_{\mathrm{b}}=\Delta \mathrm{G}_{\mathrm{int}}^{\text {ele }}+\Delta \mathrm{G}_{\mathrm{int}}^{\mathrm{vdw}}+\Delta \mathrm{G}_{\mathrm{sol}}-\mathrm{T} \Delta \mathrm{S}
$$


where $\Delta \mathbf{G}_{\mathbf{b}}$ is the binding free energy in solution, $\Delta \mathbf{G}_{\text {int }}^{\text {ele }}$ and $\Delta \mathbf{G}_{\mathbf{i n t}}^{\mathbf{v d w}}$ are the electrostatic and van der Waals interaction energies between a ligand and a protein, $\Delta \mathbf{G}_{\mathbf{s o l}}$ is the solvation energy, and $-\mathbf{T} \Delta \mathbf{S}$ is the contribution of conformational entropy to the binding. In this study, assuming that the contribution of conformational entropy to the change in $\Delta \mathbf{G}_{\mathbf{b}}$ is negligible among mutants, ${ }^{53}$ we dis regarded the entropy term in the energy estimation. $\Delta \mathbf{G}_{\text {int }}^{\text {ele }}$ and $\Delta \mathbf{G}_{\text {int }}^{\text {vdw }}$ were computed using the same parameter set as that used in the MD simulation, and no cutoff was applied for the calculation. Solvation energy $\Delta \mathbf{G}_{\text {sol }}$ was calculated using the pbsa program. The interior dielectric constant was set to $2.0^{49}$ and the outer dielectric constant was set to 80.0 . Furthermore, the contribution of each residue to the binding free energy was calculated. The total binding free energy was decomposed into the contribution from each individual residue by the MM/GBS A method. The modified GB model developed by Onufriev, Bashford, and $\mathrm{Cas}^{54}$ was used to calculate the solvation energy term. The MM/GBSA results were highly correlated with the MM/PBSA results, as we described previously. ${ }^{34}$ 


\section{References}

(1) Joint United Nations Programme on HIV/AIDS (UNAIDS). (2006) 2006 report on the global AIDS epidemic. UNAIDS. Geneva, Switzerland.

(2) Krausslich, H. G. \& Wimmer, E. (1988). Viral prote inas es. Anu. Rev. Biochem. 57, 701-754.

(3) Kohl, N. E., Emini, E. A., Schleif, W. A., Davis, L. J., Heimbach, J. C., Dixon, R. A., Scolinick, E. M. \& Sigal, I. S. (1988). Active human immunodeficiency virus protease is required for viral in fectivity. Proc. Natl. Acad. Sci. USA 85, 4686-4690.

(4) Craig, J. C., Duncan, I. B., Hockley, D., Grief, C., Roberts, N. A. \& Mills, J. S. (1991). Antiviral properties of Ro 31-8959, an inhibitor of human immuno deficiency virus (HIV) proteinase. Antiviral. Research 16, 295-305.

(5) Vacca, J. P., Dorsey, B. D., Schleif, W. A., Leven, R. B., McDaniel, S. L., Darke, P. L., Zugay, J., Quintero, J. C., Blahy, O. M., Roth, E., Sardana, V. V., Schlabach, A. J., Graham, P. I., Condra, J. H., Gotlib, L., Holloway, M. K., Lin, J., Chen, L.-W., Vastag, K., Ostvic, D., Anderson, P. S., Emini, E. A. \& Huff, J. R. (1994). L-735,524: an orally bioavailable human immunodeficiency virus type 1 protease inhibitor. Proc. Natl. Acad.Sci. USA 91, 4096-4100.

(6) Kempf, D. J., Marsh, K. C., Denissen, J. F., McDonald, E., Vas avanonda, S., Flentga, C. A., Green, B. E., Fino, L., Park, C. H., Kong, X., Wideburg, N. E., Saldivar, A., Ruiz, L., Kati, W. M., Sham, H. L., Robins, T., Stewart, K. D., Hsu, A., Plattner, J. J., Leonard, J. M. \& Norbeck, D. W. (1995). ABT-538 is a potent inhibitor of human immunodefic iency virus protease and has high oral bioavailability in humans. Proc. Natl. Acad. Sci. USA 92 , 2484-2488.

(7) Livington, D. J., Pazhanisamy, S., Porter, D. J., Partaledis, J. A., Tung, R. D. \& Painter, G. R. (1995). Weak binding of VX-478 to human plasma proteins and implications for anti-human 
immunodefic iency virus therapy. J. Infect. Dis. 172, 1238-1245.

(8) Patick, A. K., Mo, H., Markowitz, M., Appelt, K., Wu, B., Musick, L., Kalish, V., Kaldor, S., Reich, S., Ho, D. \& Webber, S. (1996). Antiviral and resistance studies of AG1343, an orally bioavailable inhibitor of human immunodeficiency virus protease. Antimicrob. Agents Chemother. 40, 292-297 (Erratum, 40, 1575).

(9) Carrillo, A., Stewart, K. D., Sham, H. L., Norbeck, D. W., Kohlbrenner, W. E., Leonard, J. M., Kempf, D. J. \& Molla, A. J. (1998). In vitro selection and characterization of human immunodefic iency virus type 1 variants with increased resistance to ABT-378, a novel protease inhibitor. J. Virol. 72, $7532-7541$.

(10) Robinson, B. S., Riccardi, K. A., Gong, Y. F., Guo, Q., Stock, D. A., Blair, W. S., Terry, B. J., Deminie, C. A., Djang, F., Colonno, R. J. \& Lin, P. F. (2000). BMS-232632, a highly potent human immunodeficiency virus protease inhibitor that can be used in combination with other available antiretroviral agents. Antimicrob. Agents Chemother. 44, 2093-2099.

(11) Larder, B. A., Hertogs, K., Bloor, S., van den Eynde, C., DeCian, W., Wang, Y., Freimuth, W. W. \& Tarpley, G. (2000). Tipranavir inhib its broadly protease inhibitor-res is tant HIV-1 clinical samples. AIDS 14, 1943-1948.

(12) Koh, Y., Nakata, H., Maeda, K., Ogata, H., Bilcer, G., Devasamudram, T., Kincaid, J. F., Boross, P., Wang, Y. F., Tie, Y., Volarath, P., Gadd is, L., Harrison, R. W., Weber, I. T., Ghosh, A. K. \& Mitsuya, H. (2003). Novel bis-tetrahydrofuranylurethane-containing nonpeptidic protease inhibitor (PI) UIC-94017 (TMC114) with potent activity aga inst multi-PI-res istant human immunodefic iency virus in vitro. Antimicrob. Agents Chemother. 47, 3123-3129.

(13) Cornelis sen, M., van den Burg, R., Zorgdrager, F., Lukashov, V. \& Goudsmit, J. (1997). pol gene 
diversity of five human immunodeficiency virus type 1 subtypes: evidence for naturally occurring mutations that contribute to drug resistance, limited recombination patterns, and common ancestry for subtypes B and D. J. Virol. 71, 6348-6358.

(14) Pieniazek, D., Rayfield, M., Hu, D. J., Nkengas ong, J., Wiktor, S. Z., Downing, R., Biryahwaho, B., Mastro, T., Tanuri, A., Soriano, V., Lal, R. \& Dondero, T. (2000). Protease sequences from HIV-1 group $\mathrm{M}$ subtypes A-H reveal distinct amino acid mutation patterns associated with protease resistance in protease inhibitor-naive individuals worldwide. HIV variant working group. AIDS 14, 1489-1495.

(15) Vergne, L., Peeters, M., Mpoudi-Ngole, E., Bourgeois, A., Liegeois, F., Toure-Kane, C., Mboup, S., Mulanga-Kabeya, C., Saman, E., Jourdan, J., Reynes, J. \& Delaporte, E. (2000). Genetic diversity of protease and reverse transcriptase sequences in non-subtype-B human immunodeficiency virus type 1 strains: evidence of many minor drug res istance mutations in treatment-naive patients. J. Clin. Microbiol. 38, 3919-3925.

(16) Grossman, Z., Vardinon, N., Chemtob, D., Alkan, M. L., Bentwich, Z., Burke, M., Gottesman, G., Istomin, V., Levi, I., Maayan, S., Shahar, E. \& Schapiro, J. M. (2001). Genotypic variation of HIV-1 reverse trans criptase and proteas e: comparative analys is of clade $\mathrm{C}$ and clade $\mathrm{B}$. AIDS 15, 1453-1460 (Erratum, 15, 2209).

(17) Ariyoshi, K., Matsuda, M., Miura, H., Tateishi, S., Yamada, K. \& Sugiura, W. (2003). Patterns of point mutations associated with antiretroviral drug treatment failure in CRF01_AE (subtype E) infection differ from subtype B infection. JAIDS 33, 336-342.

(18) Clemente, J. C., Coman, R. M., Thiaville, M. M., Janka, L. K., Jeung, J. A., Nukoolkarn, S., Govindasamy, L., Agbandje-McKenna, M., McKenna, R., Leelamanit, W., Goodenow, M. M. \& 
Dunn, B. M. (2006). Analys is of HIV-1 CRF_01 A/E protease inhibitor resistance: structural determinants for maintaining sensitivity and developing resistance to atazanavir. Biochemistry $\mathbf{4 5}$, $5468-5477$.

(19) Sugiura, W., Matsuda, Z., Yokomaku, Y., Hertogs, K., Larder, B., Oishi, T., Okano, A., Shiino, T., Tatsumi, M., Matsuda, M., Abumi, H., Takata, N., Shirahata, S., Yamada, K., Yoshikura, H. \& Nagai, Y. (2002). Interference between D30N and L90M in selection and development of protease inhibitor-resistant human immunodeficiency virus type 1. Antimicrob. Agents Chemother. 46, 708-715.

(20) $\mathrm{J}$ o $\mathrm{h} n \mathrm{~s}$ o $\mathrm{n}, \quad \mathrm{V} . \quad \mathrm{A} ., \quad \mathrm{B} \mathrm{r} \mathrm{n}-\mathrm{V}$ ézinet, $\quad \mathrm{F}$, C 1 o $\mathrm{t}$ e $\mathrm{t}, \mathrm{B}$. , Kuritzuk e $\mathrm{s}, \quad \mathrm{D} . \quad \mathrm{R} ., \quad$ Pillay, $\mathrm{D}$. , Schapiro , J . M . \& Richman, D. D . (2006). U p d a t e o f $\mathrm{t} h$ e $\quad \mathrm{d} \quad \mathrm{r}$ u $\mathrm{g}$ resistant mutation in $\mathrm{H} \mathrm{I} \mathrm{V}-1$ : fall 2006.

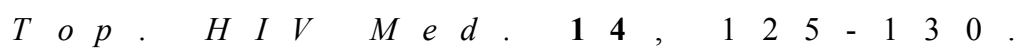

(21) Cane, P. A., Ruiter, A., Rice, P., Wis elka, M., Fox, R. \& Pillay, D. (2001). Resistance-associated mutations in the human immunodeficiency virus type 1 subtype $\mathrm{C}$ protease gene from treated and untreated patients in the United Kingdom. J. Clin. Microbiol. 39, 2652-2654.

(22) Grossman, Z., Paxinos, E. E., Averbuch, D., Maayan, S., Parkin, N. T., Engelhard, D., Lorber, M., Istomin, V., Shaked, Y., Mendelson, E., Ram, D., Petropoulos, C. J. \& Schapiro, J. M. (2004). Mutation D30N is not preferentially selected by human immunodeficiency virus type 1 subtype $\mathrm{C}$ in the development of resistance to nelfinav ir. Antimicrob. Agen ts Chemother. 48, 2159-2165.

(23) Gonzalez, L. M. F., Brindeiro, R. M., Aguiar, R.S., Pereira, H. S., Abreu, C. M., Soares, M. A. \& Tanuri, A. (2004). Impact of nelfinavir resistance mutations on in vitro phenotype, fitness and 
replication capacity of human immunodeficiency virus type 1 with subtype B and C proteases. Antimicrob. Agents Chemother. 48, 3552-3555.

(24) Kantor, R., Katzenstein, D. A., Efron, B., Carvalho, A. P., Whynhoven, B., Cane, P., Clarke, J., Sirivichayakul, S., Soares, M. A., Snoeck, M. A., Pillay, C., Rudich, H., Rodrigues, R., Holguin, A., Aariyoshi, K., Bouzas, M. B., Cahn, P., Sugiura, W., Soriano, V., Brigido, L. F., Grossman, Z., Morris, L., Vandamme, A.-M., Tanuri, A., Phanuphak, P., Weber, J. N., Pillay, D., Harrigan, P. R., Camacho, R., Schapriro, J. M. \& Shafer, R. W. (2005). Impact of HIV-1 subtype and antiretroviral therapy on protease and reverse transcriptase genotype: results of a global collaboration. Pros Med. 2 , e112.

(25) Billingam, D. (2006). Does the world need another AIDS authority? THE LANCET 368, 1639-1640.

(26) Kantor, R. \& Katzenstein, D. (2003). Polymorphism in HIV-1 non-subtype B protease and reverse transcriptase and its potential impact on drug susceptibility and drug res is tance evolution. AIDS Rev. 5, 25-35.

(27) Nkengasong, J., N. Adje-Toure, C. \& Weidle, P. J. (2004). HIV antiretroviral drug resistance in Afric a. AIDS Rev. 6, 4-12.

(28) Ode, H., Ota, M., Neya, S., Hata, M., Sugiura, W. \& Hoshino, T. (2005). Resistant mechanism against nelfinavir of human immunodeficiency virus type-1 proteases. J. Phys. Chem. B 109, $565-574$.

(29) Skalova, T., Dohnalek, J., Duskova, J., Petrokova, H., Hradilek, M., Soucek, M., Konvalinka, J. \& Hasek, J. (2006). HIV-1 protease mutations and inhibitor modifications monitored on a series of complexes. Structural basis for the effect of the A71V mutation on the active site. J Med Chem. 49, $5777-5784$.

(30) Piana, S., Carloni, P. (2002). Roth lis berger, U. Drug res istance in HIV-1 proteas e: flex ib ility-ass is ted 
mechanism of compensatory mutations. Protein Sci. 11, 2393-2402.

(31) Ode, H., Neya, S., Hata, M., Sugiura, W. \& Hoshino, T. (2006). Computational simulations of HIV-1 proteases-multi-drug resistance due to nonactive site mutation L90M. J. Am. Chem. Soc. 128, 7887-7895.

(32) Meiselbach, H., Horn, A. H. C., Harrer, T. \& Sticht, H. (2006). Ins ights into amprenav ir res istance in E35D HIV-1 protease mutation from molecular dynamics and binding free-energy calculations. $J$. Mol. Model. 13, 297-304.

(33) Batista, P. R., Wilter, A., Durham, E. H. \& Pascutti, P. G. (2006). Molecular dynamics simulations applied to the study of subtypes of HIV-1 protease common to Brazil, Africa, and Asia. Cell Biochem. Biophys. 44, 395-404.

(34) Ode, H., Matsuyama, S., Hata, M., Hoshino, T., Kakizawa, J. \& Sugiura, W. (2007). Mechanism of drug resistance due to N88S in CRF01_AE HIV-1 protease, analyzed by molecular dynamics simulations. J. Med. Chem. 50, 1768-1777.

(35) Clemente, J. C., Hermrajani, R., Blum, L. E., Goodenow, M. M. \& Dunn, B. M. (2003). Secondary mutations $\mathrm{M} 36 \mathrm{I}$ and $\mathrm{A} 71 \mathrm{~V}$ in the human immunodefic iency virus type 1 protease can provide an advantage for the emergence of the primary mutation D30N. Biochemistry 42, 15029-15035.

(36) Kaldor, S. W., Kalish, V. J., Davies, J. F., Shetty, B. V., Fritz, J. E., Appelt, K., Burgess, J. A., Campanale, K. M., Chirgadze, N. Y., Clawson, D. K., Dressman, B. A., Hatch, S. D., Khalil, D. A., Kosa, M. B., Lubbehus en, P. P., Muesing, M. A., Patick, A. K., Reich, S. H., Su, K. S. \& Tatlock, J. H. (1997). Viracept (nelfinavir mesylate, AG1343): a potent, orally bioavailable inhibitor of HIV-1 protease. J. Med. Chem. 40, 3979-3985.

(37) Abecasis, A. B., Deforche, K., Snoeck, J., Bacheler, L. T., McKenna, P., Carvalho, A. P., Gomes, P., 
Camacho, R. J. \& Vandamme, A.-M. (2005). Protease mutation M89I/V is linked to therapy failure in patients infected with the HIV-1 non-B subtypes C, F or G. AIDS 19, 1799-1806.

(38) Case, D. A., Darden, T. A., Cheatham, T. E. III, Simmerling, C. L., Wang, J., Duke, R. E., Luo, R., Merz, K. M., Wang, B., Pearlman, D. A., Crowley, M., Brozell, S., Tsui, V., Gohlke, H., Mongan, J., Hormak, V., Cui, G., Beroza, P., Schafmeister, C., Caldwell, J. W., Ross, W. S. \& Kollman, P. A. (2004). AMBER 8, University of California, San Franc isco.

(39) Duan, Y., Wu, C., Chowdhury, S., Lee, M. C., Xiong, G., Zhang, W., Yang, R., Cieplak, P., Luo, R. \& Lee, T. (2003). A point-charge force field for molecular mechanics simulations of proteins based on condensed-phase quantum mechanical calculations. J. Comput. Chem. 24, 1999-2012.

(40) Wang, J., Wolf, R. M., Caldwell, J. W., Kollman, P. A. \& Case, D. A. (2004). Development and testing of a general Amber force field. J. Comput. Chem. 25, 1157-1174.

(41) Jorgensen, W. L., Chandrasekhar, J., Madura, J. D., Impey, R. W. \& Klein, M. L. (1983). Comparison of simple potential functions for simulating liquid water. J. Chem. Phys. 79, 926-935.

(42) Ryckaert, J.-P., Ciccotti, G. \& Berendsen, H. J. C. (1977). Numerical integration of the cartes ian equations of motion of a system with constrain ts: molecular dynamics of n-alkanes. J. Comput. Phys. 23, 327-341.

(43) Zoete, V., Michielin, O. \& Karplus, M. (2002). Relation between sequence and structure of HIV-1 protease inhibitor complexes: a model system for the analysis of protein flex ib ility. J. Mol. Biol. $\mathbf{3 1 5}$, $21-52$

(44) Roberts, N. A., Martin, J. A., Kinchington, D., Broadhurst, A. V., Craig, J. C., Dunc an, I. B., Galpin, S. A., Handa, B. K., Kay, J., Krohn, A., Lambert, R. W., Merrett, J. H., Millis, J. S., Parkes, K. E. B., Redshaw, S., Ritchie, A. J., Taylor, D. L., Thomas, G. J. \& Machin, P. J. (1990). Rational design of 
peptide-based HIV proteinase inhibitors. Science 248, 358-361.

(45) Krohn, A., Redshaw, S., Ritchie, J. C., Graves, B. J. \& Hatada, M. H. (1991). Novel binding mode of highly potent HIV-proteinase inhibitors incorporating the (R)hydroxyethylamine isostere. J. Med. Chem. 34, 3340-3342.

(46) Okimoto, N., Tsukui, T., Hata, M., Hoshino, T. \& Tsuda, M. (1999). Hydrolys is mechanism of the phenylalanine-proline peptide bond specific to HIV-1 protease: investigation by the ab initio mo lecular orbital method. J. Am. Chem. Soc. 121, 7349-7354.

(47) Srinivasan, J., Cheatham, T. E. III, Kollman, P. \& Case, D. A. (1998). Continuum solvent studies of the stability of DNA, RNA, and phosphoramidate-DNA helic es. J. Am. Chem. Soc. 120, 9401-9409.

(48) Kollman, P. A., Massova, I., Reyes, C., Kuhn, B., Huo, S., Chong, L., Lee, M., Lee, T., Duan, Y., Wang, W., Donini, O., Cieplak, P., Srinivasan, J., Case, D. A. \& Cheatham, T.E. III. (2000). Calculating structures and free energies of complex molecules: combining molecular mechanics and continuum models. Accts. Chem. Res. 33, 889-897.

(49) Wang, W. \& Kollman, P. A. (2000). Free energy calculations on dimer stability of the HIV protease using molecular dynamics and a continuum solvent model. J. Mol. Biol. 303, 567-582.

(50) Liang, J., Edelsbrunner, H. \& Woodward, C. (1998). Anatomy of prote in pockets and cavities: meas urement of bind ing site geometry and implications for ligand design. Protein Sci. 7,1884-1897.

(51) Richardson, J.S., Richardson, D.C. (2001) MAGE, PROBE, and Kinemages, Chapter 25.2.8. In: Rossmann, M.G., Arnold, E. (eds.) International Tables for Crystallography, vol. F, pp. 727-730. Kluwer Publishers, Dord recht

(52) Kollman, P. (1993). Free energy calculations: applic ations to chemical and biochemic al phenomena. Chem. Rev. 93, 2395-2417. 
(53) Massova, I. \& Kollman, P. A. (2000). Combined molecular mechanical and continuum solvent appproach (MM-PBSA/GBSA) to predict ligand binding. Perspect. Drug. Discovery Des. 18, $113-135$.

(54) Onufriev, A., Bashford, D. \& Case, D. A. (2004). Exploring protein native states and largescale conformational changes with a modified generalized born model. Proteins 55, 383-394. 


\section{Figure legends}

Fig. 1. a: Structure of HIV-1 PR in complex with NFV. Locations of two cataly tic aspartates, the 30th and the 36th residues, and NFV are shown in ball and stick representations. The amino acid sequence of subtype B wild-type (WT) HIV-1 PR (HXB2) and that of M36I mutant are shown under the structure. b: Chemic al s truc ture of NFV.

Fig. 2. Distance between the 30th residue of PR and NFV. Red and green solid lines correspond to the distance between $\mathrm{N}$ of the 30th residue and $\mathrm{O} 1$ ato m of $\mathrm{NFV}$ and that between $\mathrm{O}$ of the 30th residue and O1 atom of NFV, respectively. Blue solid lines of $\mathrm{B}(\mathrm{WT}), \mathrm{B}(\mathrm{M} 36 \mathrm{I})$, and $\mathrm{B}(\mathrm{M} 36 \mathrm{~V})$ show the distance between OD1/OD2 of $\mathrm{D} 30$ and $\mathrm{O} 1$ atom of $\mathrm{NFV}$, while those of $\mathrm{B}(\mathrm{D} 30 \mathrm{~N}), \mathrm{B}(\mathrm{D} 30 \mathrm{~N} / \mathrm{M} 36 \mathrm{I})$, and $\mathrm{B}(\mathrm{D} 30 \mathrm{~N} / \mathrm{M} 36 \mathrm{~V})$ are the dis tance between $\mathrm{OD} 1 / \mathrm{ND} 2$ of $\mathrm{N} 30$ and $\mathrm{O} 1$ atom of NFV.

Fig. 3. 3D plot of RMSD of the average structure of each model from that of $B(W T)$. $P R$ is shown in colored tube representations. Color indicates the magnitude of RMSD shown in the bottom bar. Each model was fitted to $\mathrm{B}(\mathrm{WT})$ using the coordinates of main chain atoms $\mathrm{N}, \mathrm{Ca}$, and $\mathrm{C}$ of PR. The sup erimpos ed gray tubes repres ent the average structure of B(WT).

Fig. 4. Interactions of the 36th residues with L33 and with V77. The average structure of B(WT) was superimposed onto that of $\mathrm{B}(\mathrm{M} 36 \mathrm{I})$ using the coordinates of $\mathrm{N}, \mathrm{C} \alpha$, and $\mathrm{C}$ atoms. The superimposed structure of $\mathrm{B}(\mathrm{WT})$ was shown in gray sticks and cartoons repres entation. The orange arrow indicated the locations of the 80's loop, where a prominent change of conformation occurred by M36I.

Fig. 5. Positional shift of each residue measured from the center of the binding cavity in the average coordinate of WT PR. Negative values ind ic ate contraction of distances measured from the center of the cavity, and positive values ind icate elongation of the distances. Bottom black lines represent the locations of the active site residues. 
TABLES

Table 1. Hydro gen bond networks of NFV with D30 or N30 in PR.

\begin{tabular}{|c|c|c|c|c|c|c|c|c|c|}
\hline \multicolumn{2}{|c|}{ Donor } & \multicolumn{2}{|c|}{ Acc ep tor } & \multirow[t]{2}{*}{$\%^{a}$} & \multicolumn{2}{|r|}{ Donor } & \multicolumn{2}{|c|}{ Acceptor } & $\%$ \\
\hline \multicolumn{4}{|c|}{ WT } & & \multicolumn{5}{|c|}{$\mathrm{D} 30 \mathrm{~N}$} \\
\hline $\mathrm{N}$ & D30 & $\mathrm{O} 1^{b}$ & NFV & 30.7 & & & & & \\
\hline $\mathrm{O} 1$ & NFV & OD1/OD2 & D30 & 31.6 & & & & & \\
\hline $\mathrm{O} 1$ & NFV & $\mathrm{O}$ & D30 & 42.9 & & & & & \\
\hline \multicolumn{5}{|c|}{ M36I } & \multicolumn{5}{|c|}{ D30N/M36I } \\
\hline $\mathrm{O} 1$ & NFV & OD2 & D30 & 95.3 & $\mathrm{O} 1$ & NFV & $\mathrm{O}$ & $\mathrm{N} 30$ & 57.1 \\
\hline \multicolumn{5}{|c|}{ M36V } & \multicolumn{5}{|c|}{$\mathrm{D} 30 \mathrm{~N} / \mathrm{M} 36 \mathrm{~V}$} \\
\hline $\mathrm{N}$ & D30 & O1 & NFV & 18.0 & $\mathrm{~N}$ & N30 & O1 & NFV & 24.9 \\
\hline $\mathrm{O} 1$ & NFV & OD1/OD2 & D30 & 46.1 & & & & & \\
\hline O1 & NFV & $\mathrm{O}$ & D30 & 35.9 & $\mathrm{O} 1$ & NFV & $\mathrm{O}$ & $\mathrm{N} 30$ & 34.7 \\
\hline
\end{tabular}

$a$ Occupancy of hydrogen bonds during the 2.0-3.0 ns MD simulation.

$b$ The atom names of NFV are shown in Fig. 1. 
Table 2. Volume and surface area of the bind ing cavity in each model.

\begin{tabular}{lcccccc}
\hline \hline & WT & M36I & M36V & D30N & $\begin{array}{c}\text { D30N } \\
\text { /M36I }\end{array}$ & $\begin{array}{c}\text { D30N } \\
\text { /M36V }\end{array}$ \\
\hline Volume & 375 & 345 & 365 & 403 & 419 & 375 \\
$\left(\AA^{3}\right)$ & $( \pm 43)^{a}$ & $( \pm 36)$ & $( \pm 43)$ & $( \pm 53)$ & $( \pm 53)$ & $( \pm 47)$ \\
\hline Surface & 490 & 471 & 469 & 508 & 506 & 484 \\
Area $\left(\AA^{2}\right)$ & $( \pm 43)$ & $( \pm 35)$ & $( \pm 47)$ & $( \pm 40)$ & $( \pm 54)$ & $( \pm 48)$ \\
\hline
\end{tabular}

$a$ The stand ard deviations were written in the parenthes es. 
Table 3. Binding free energy of each model.

\begin{tabular}{l|cccc:c|c}
\hline \hline & $\begin{array}{c}\Delta \mathbf{G}_{\text {int }}^{\text {ele }} \\
(\mathrm{kcal} / \mathrm{mol})\end{array}$ & $\begin{array}{c}\Delta \mathbf{G}_{\text {int }}^{\text {vdw }} \\
(\mathrm{kcal} / \mathrm{mol})\end{array}$ & $\begin{array}{c}\Delta \mathbf{G}_{\text {sol }} \\
(\mathrm{kcal} / \mathrm{mol})\end{array}$ & $\begin{array}{c}\Delta \mathbf{G}_{\mathbf{b}}{ }^{a} \\
(\mathrm{kcal} / \mathrm{mol})\end{array}$ & $\begin{array}{c}\Delta \mathbf{G}_{\mathbf{b}} \\
(\mathrm{kcal} / \mathrm{mol})\end{array}$ & $\begin{array}{c}\mathrm{IC50}^{b} \\
(\mathrm{nM})\end{array}$ \\
\hline $\mathrm{WT}$ & $-12.5 \pm 1.4$ & $-71.8 \pm 3.8$ & $15.1 \pm 1.4$ & $-69.2 \pm 3.7$ & - & $1.2 \pm 0.2$ \\
\hline $\mathrm{M} 36 \mathrm{I}$ & $-11.8 \pm 1.2$ & $-73.3 \pm 3.7$ & $15.4 \pm 1.1$ & $-69.7 \pm 3.5$ & -0.5 & $0.9 \pm 0.1$ \\
\hline $\mathrm{M} 36 \mathrm{~V}$ & $-13.2 \pm 1.5$ & $-72.1 \pm 3.8$ & $16.5 \pm 1.3$ & $-68.8 \pm 3.6$ & 0.4 & $\mathrm{ND}^{c}$ \\
\hline $\mathrm{D} 30 \mathrm{~N}$ & $-6.9 \pm 1.2$ & $-70.5 \pm 4.1$ & $10.9 \pm 0.9$ & $-66.5 \pm 3.9$ & 2.7 & $6.8 \pm 0.9$ \\
\hline $\mathrm{D} 30 \mathrm{~N} / \mathrm{M} 36 \mathrm{I}$ & $-8.1 \pm 1.2$ & $-66.8 \pm 3.6$ & $9.8 \pm 1.1$ & $-65.0 \pm 3.5$ & 4.2 & $6.0 \pm 1.0$ \\
\hline $\mathrm{D} 30 \mathrm{~N} / \mathrm{M} 36 \mathrm{~V}$ & $-10.8 \pm 1.2$ & $-72.8 \pm 3.9$ & $13.3 \pm 1.0$ & $-70.3 \pm 4.0$ & -1.1 & $\mathrm{ND}$ \\
\hline
\end{tabular}

$a \mathrm{~T} \Delta \mathrm{S}$ is not included.

$b$ Reference from the report by Clemente et al. ${ }^{35}$

$c$ ND denotes no data. 
a

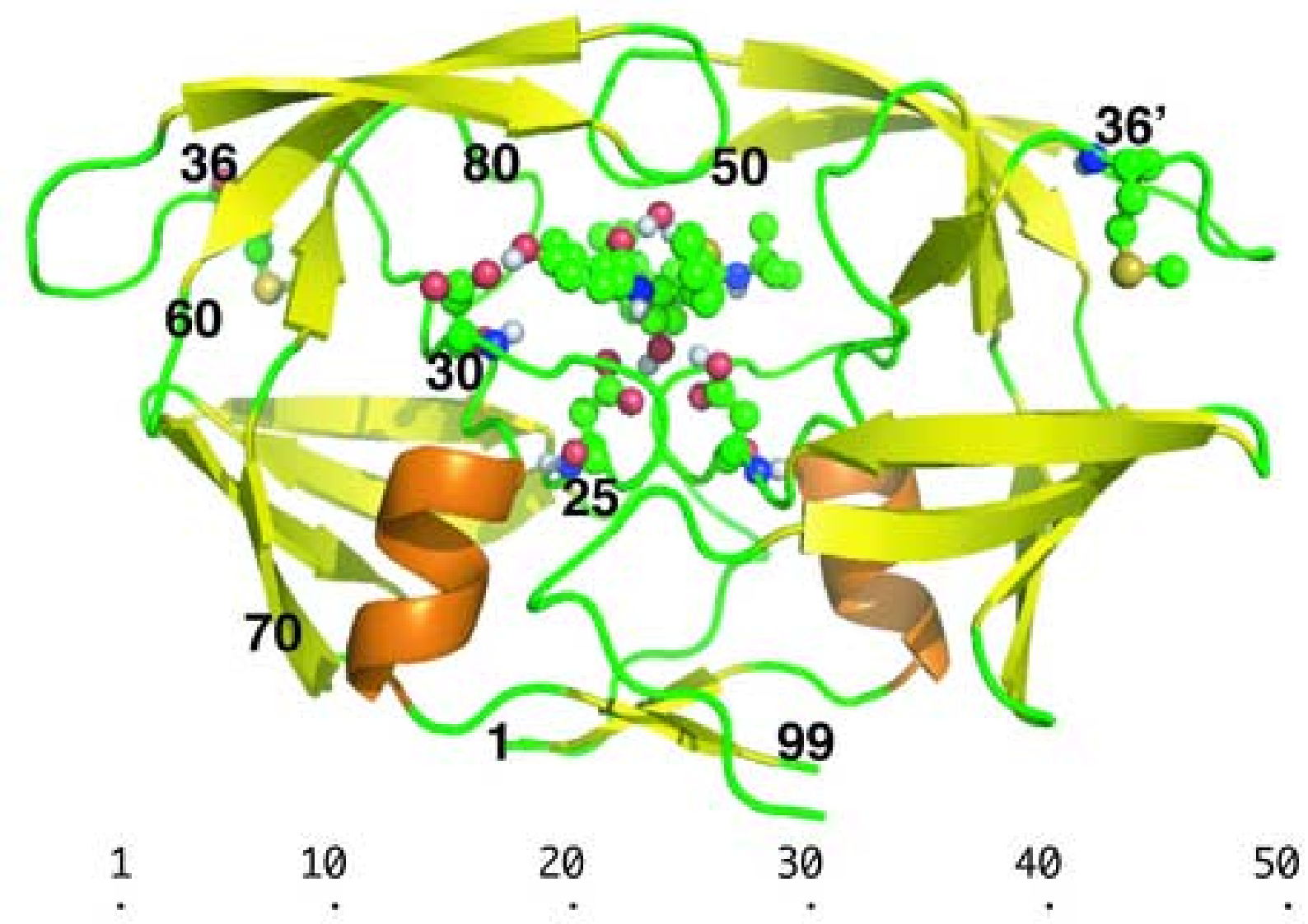

HXB2(B) : PQITLWQRPLVTIKIGGQLKEALLDTGADDTVLEEMNLPGRWKPKMIGGI M36I(B) : PQITLWQRPLVTIKIGGQLKEALLDTGADDTVLEEINLPGRWKPKMIGGI 60 70 80 90 99 HXB2(B) : GGFIKVGQYDQILIEICGHKAIGTVLVGPTPVNIIGRNLLTQIGCTLNF M36I(B) : GGFIKVGQYDQILIEICGHKAIGTVLVGPTPVNIIGRNLLTQIGCTLNF

b NFV

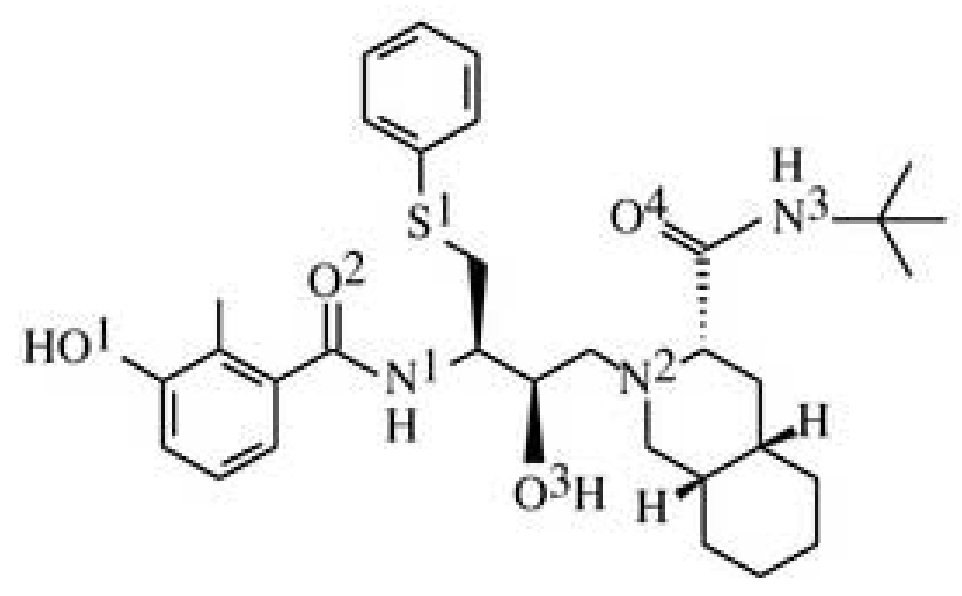




\section{Subtype B}

WT

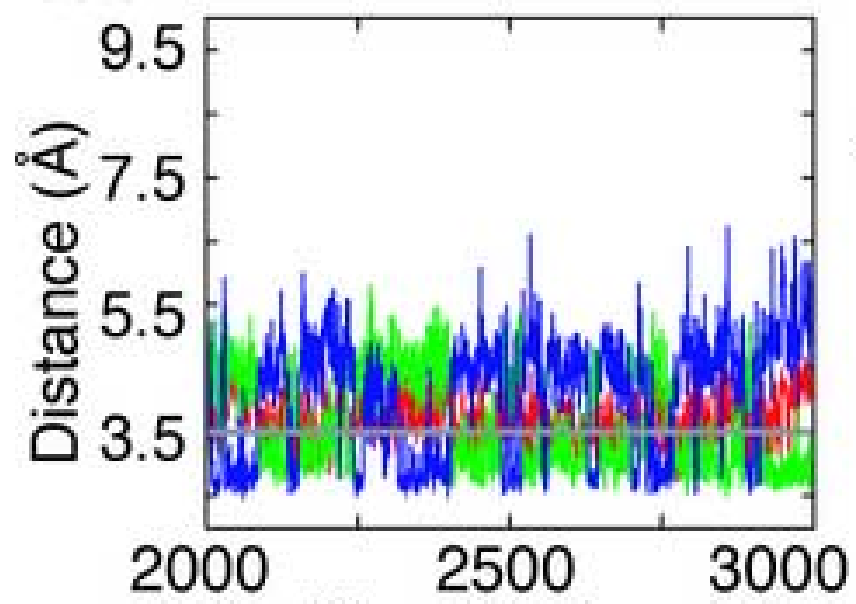

Equilibration time (ps)

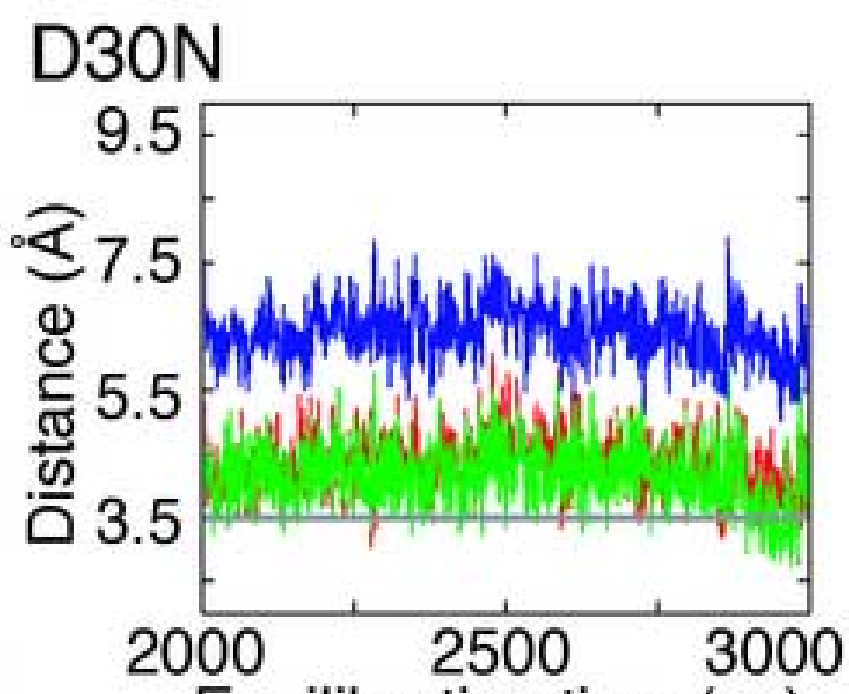

Equilibration time (ps)

M36I

D30N / M36I

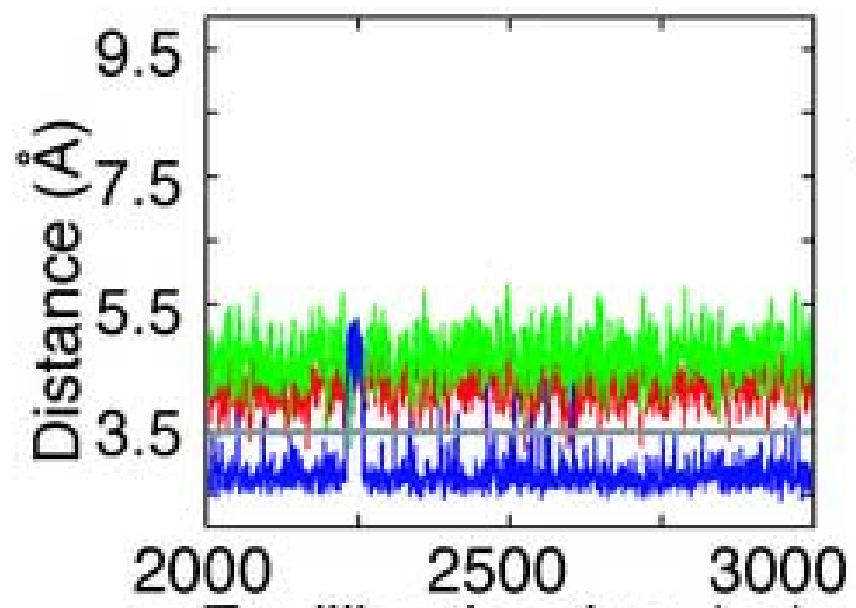

Equilibration time (ps)

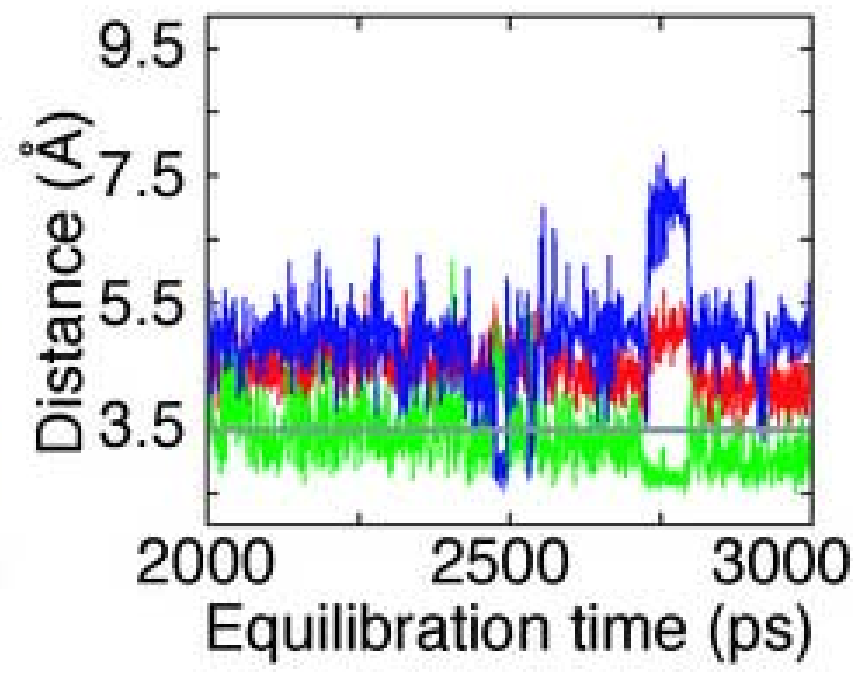

M36V

D30N / M36V

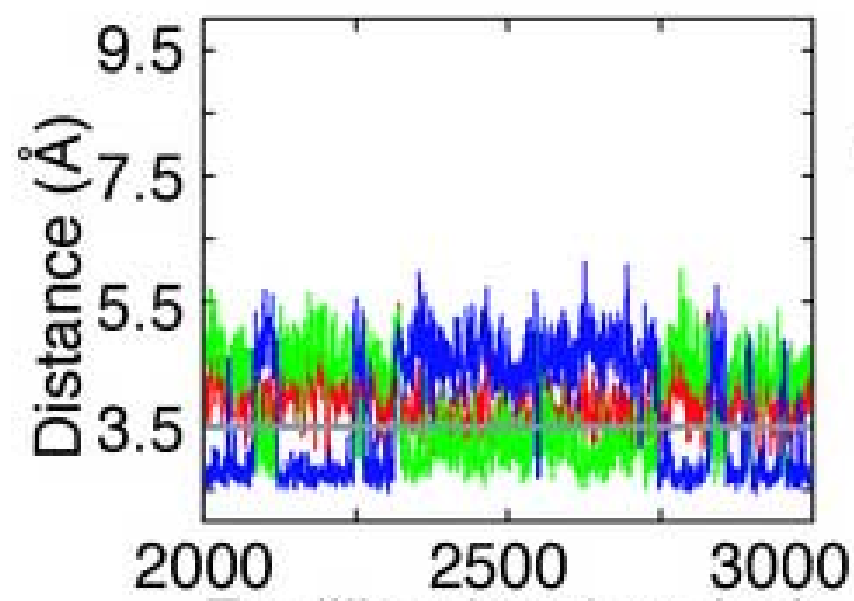

Equilibration time (ps)

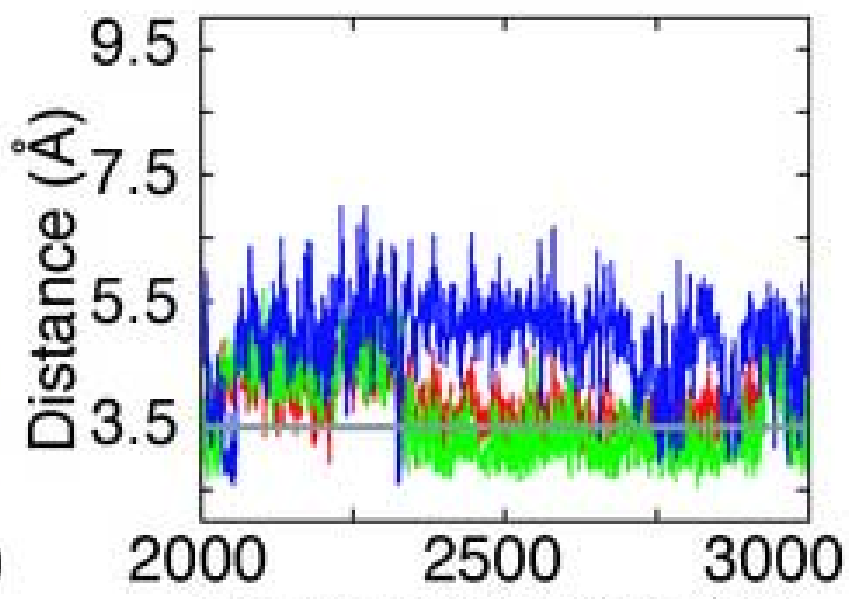

Equilibration time (ps) 
Subtype B

WT
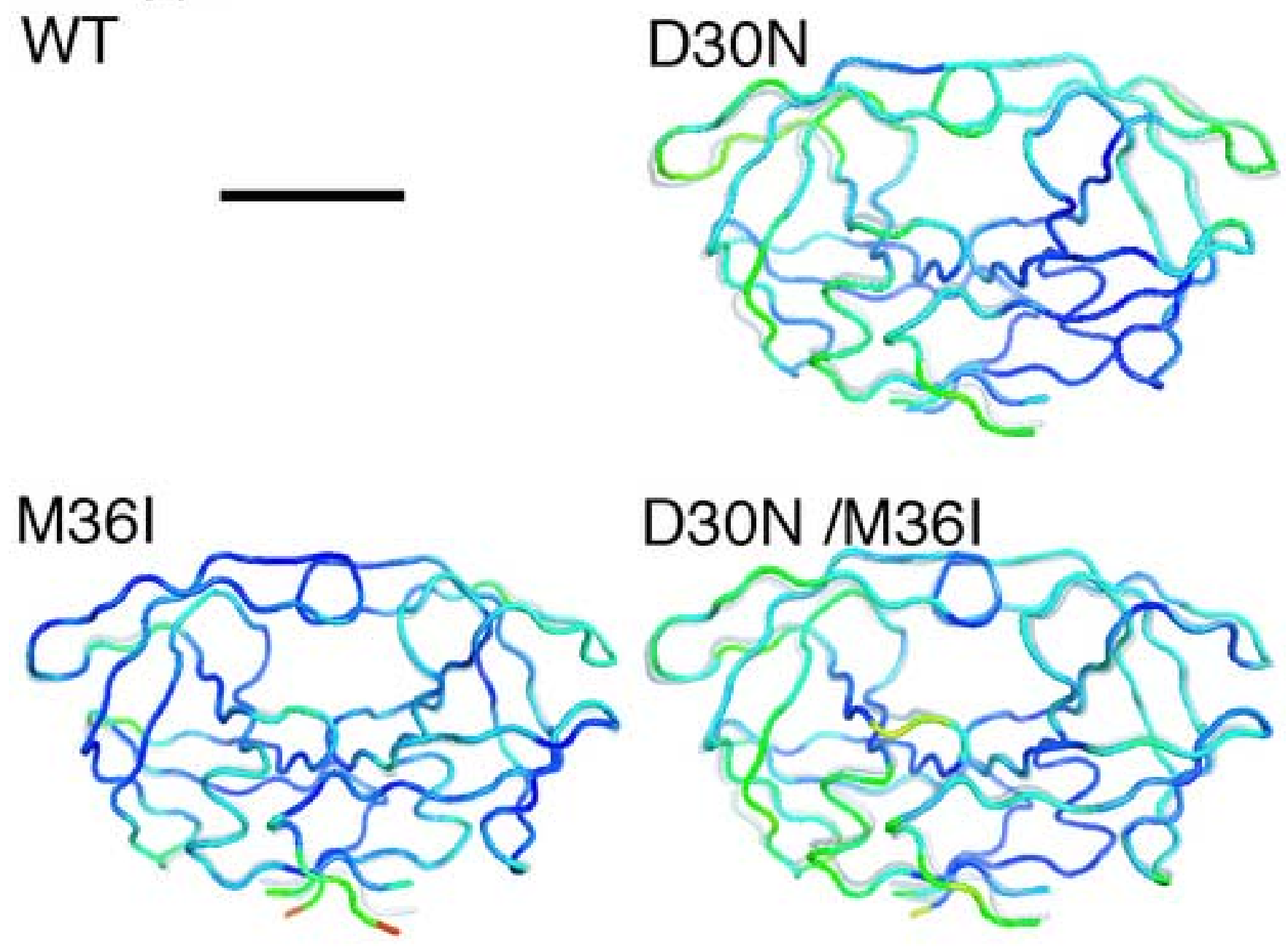

D30N/M36I

M36V

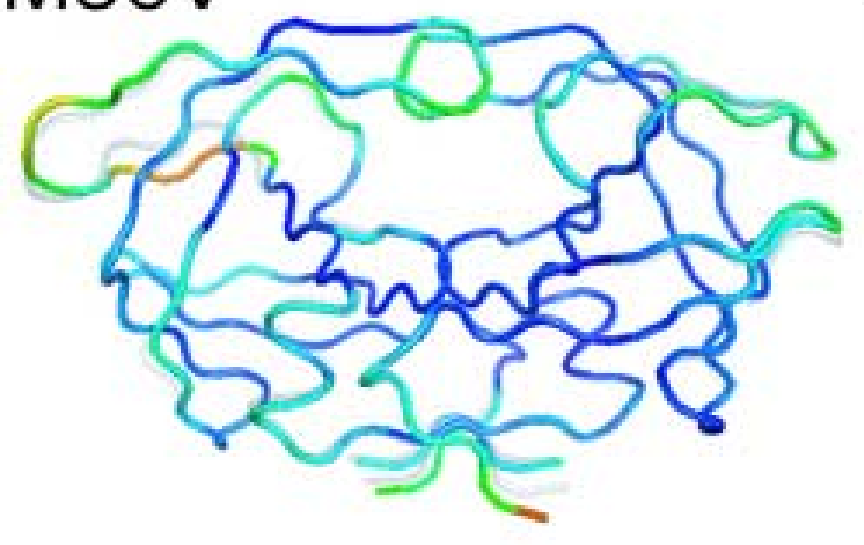

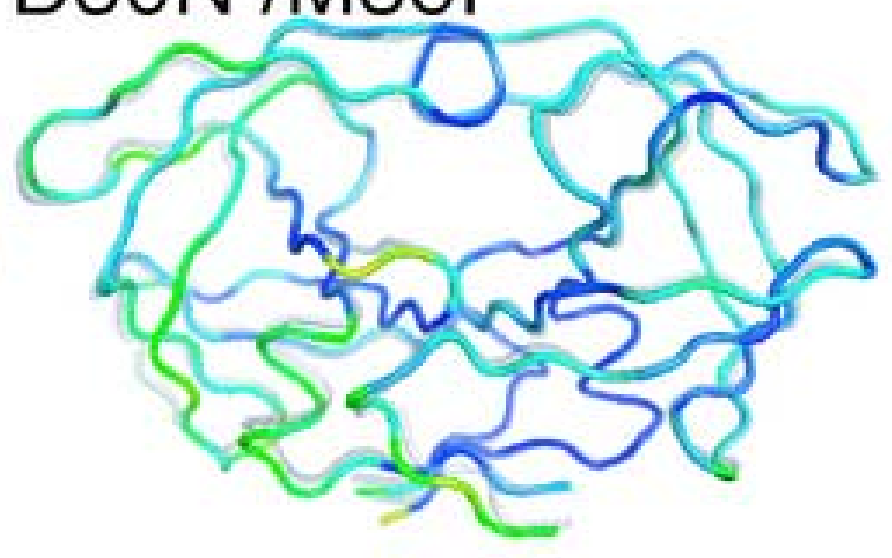

D30N /M36V

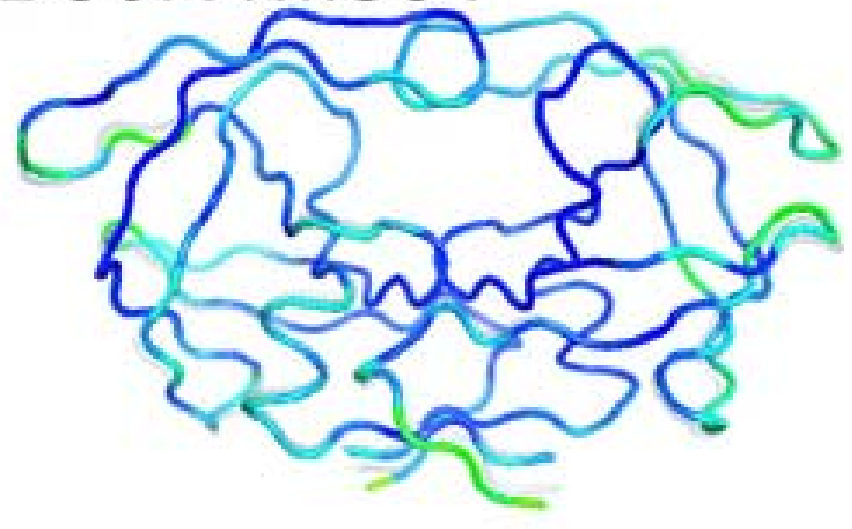

0.0

0.5

1.0

1.5

2.0

2.5

3.0(Å) 


\section{WT}
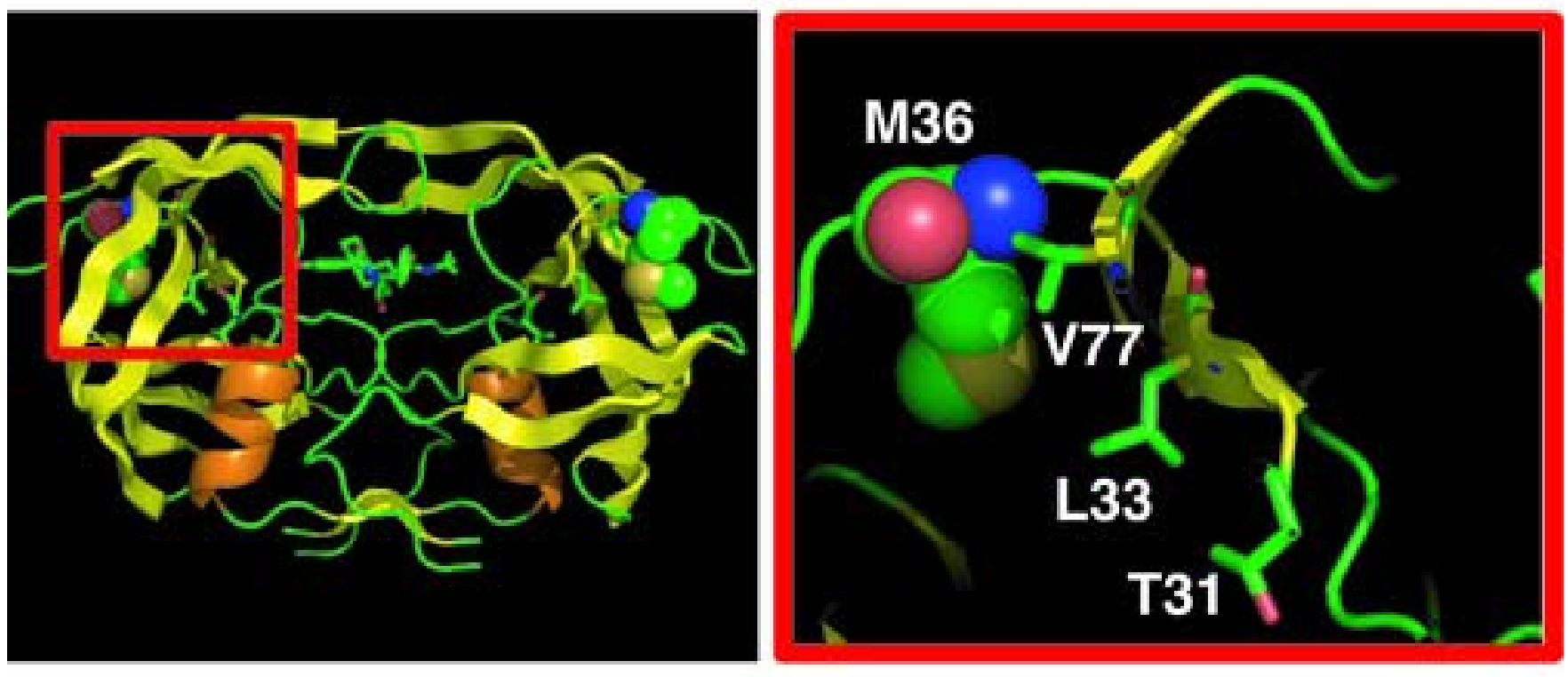

\section{M36I}
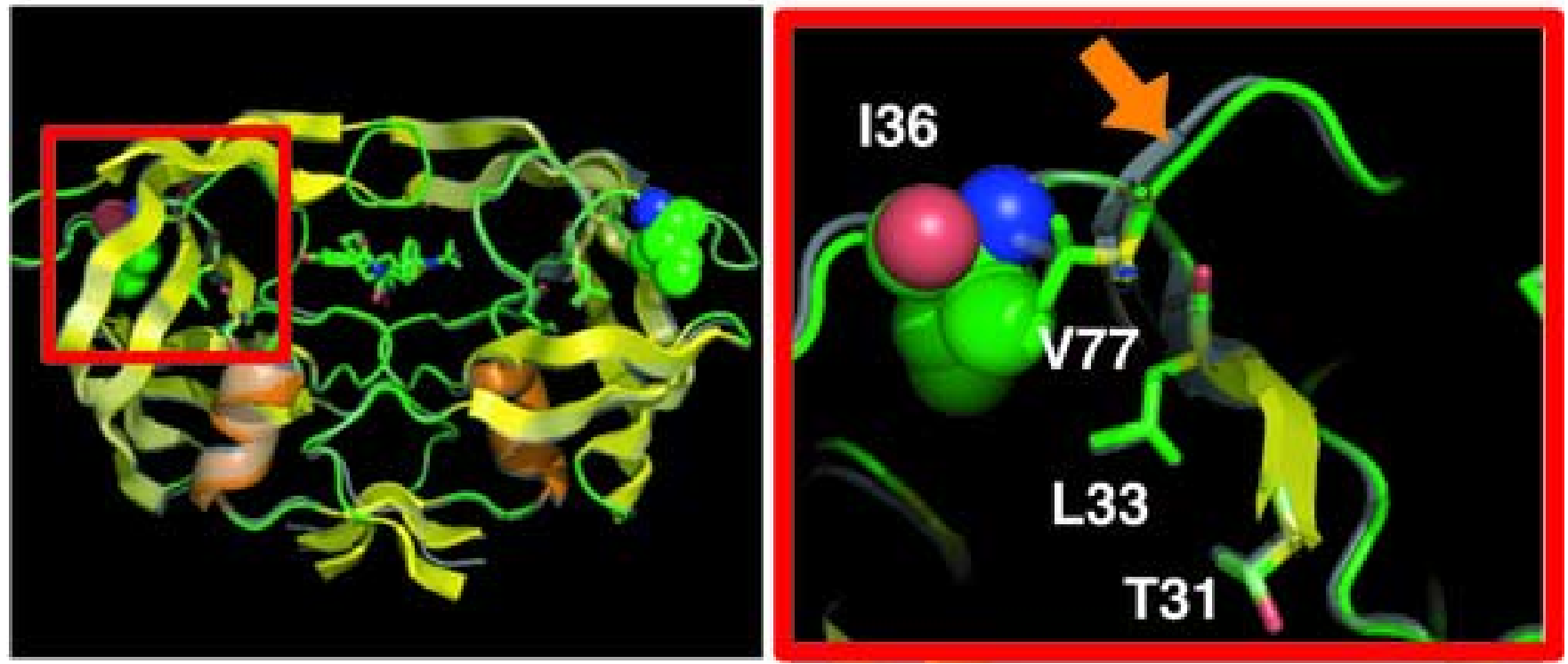
Figure 5

M361

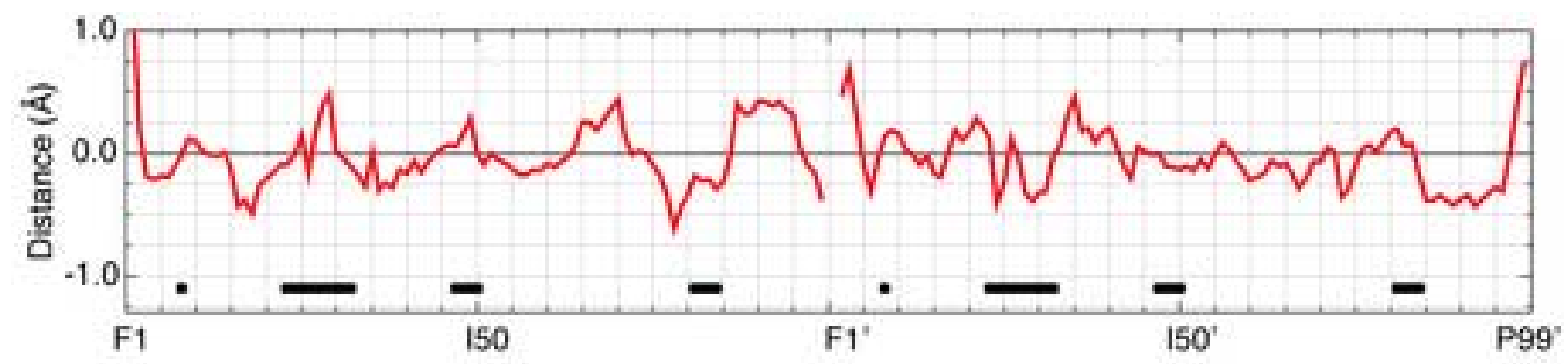

M36V

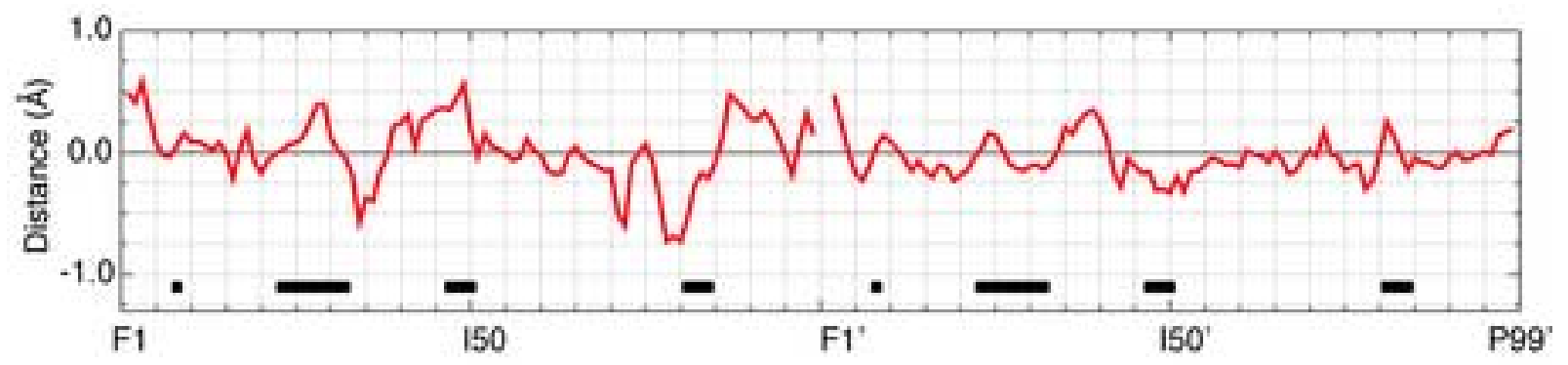

D30N
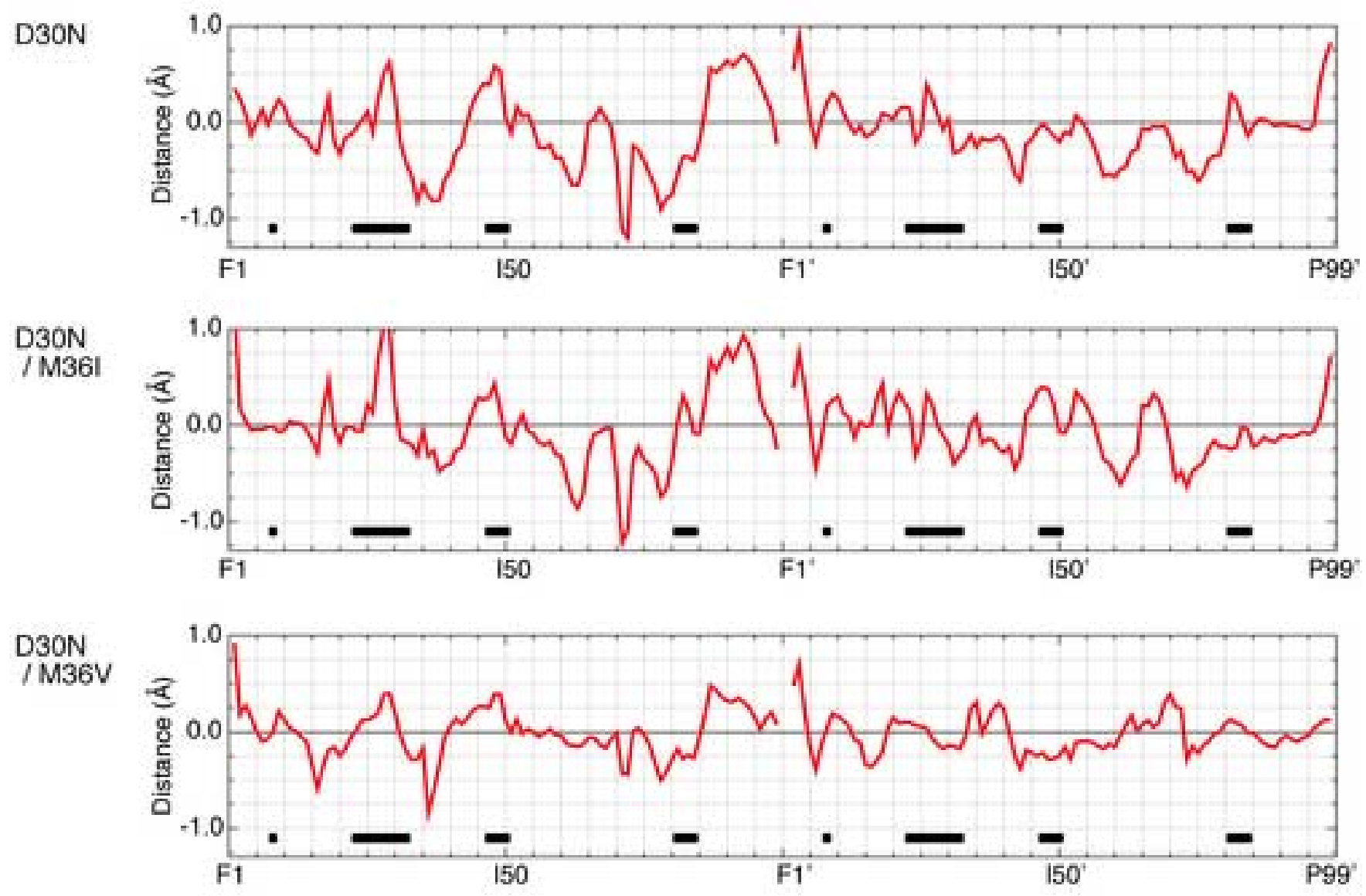